\title{
In Memoriam: Victor Semyonovich Koscheyev
}

\author{
Gloria Leon, $\mathrm{PhD} ;{ }^{1}$ Carol Amaratunga, $\mathrm{PhD} ;{ }^{2}$ Marvin Birnbaum, $\mathrm{MD}, \mathrm{PhD}^{3}$
}

1. University of Minnesota, Minneapolis, Minnesota USA

2. University of Victoria, Victoria, British Columbia, Canada; Justice Institute of British Columbia, Vancouver, British Columbia, Canada

3. University of Wisconsin-Madison, Madison, Wisconsin USA

Correspondence:

Gloria Leon, $\mathrm{PhD}$

University of Minnesota

Minneapolis, Minnesota USA

E-mail: leonx003@umn.edu

Online publication: January 11, 2019

doi:10.1017/S1049023X18001279
It is with great sadness that we note the passing of our long time WADEM colleague and friend Victor Semyonovich Koscheyev in November 2018 in Minneapolis, Minnesota (USA), having bravely battled a neuromuscular disorder for many years. Professor Koscheyev was the primary organizer of the WADEM CBRNE task force, and served as its Chair from 2003-2009. He also was a member of the WADEM Board of Directors from 2003-2011.

Victor had great visibility within WADEM and much expertise to share both nationally and internationally. His contributions were based on his involvement in disaster medicine activities in the former Soviet Union, and he continued to work in this area when he joined the University of Minnesota in 1992. Victor had unparalleled experience in disaster management and health surveillance of populations exposed to various types of CBRNE contamination. He was one of the first medical officers at Chernobyl, dealing with the health management of the general population, power plant operators, and post-disaster cleanup workers. He subsequently organized and served as first director of the Specialized Center for Disaster Medicine "Protection" in Moscow (Zaschita). In addition, he was the department head of the Russian Institute of Biophysics $\mathrm{PhD}$ program in disaster medicine. Victor was an active researcher, leading studies on physiologic and hygienic individualized protection of personnel in hazardous environments, with a focus on the development of protective clothing. He was the author/editor of 10 books and numerous papers on this topic.

Upon coming to Minnesota, one of Victor's first efforts was to organize a highly successful conference, When Everyone Leaves: Mid-and Long-term Effects of Disasters. This was a significant achievement, considering the relatively little attention paid at that time to the extended health impacts and effects on community members following a disaster. Victor participated in numerous US federal and regional government and nongovernment committees and workshops in the general area of radiation and other types of chemical and biological contamination, including the National Research Council (Washington, DC USA) Board on Radiation Effects Research and the Centers for Disease Control and Prevention (Atlanta, Georgia USA) Radiation Assessment Studies Committee. He was involved in several Bioterrorism Threat Assessment and Risk Management workshops sponsored by the Monterey Institute of International Studies (Monterey, California USA), Center for Nonproliferation Studies; planning and evaluation committees related to radiation disaster exercises carried out in Minnesota. $\mathrm{He}$ also participated as a WADEM representative to the International Atomic Energy Agency (Vienna, Austria).

Victor also had strong expertise in space-related areas, applying his academic foundation in thermal physiology to conduct extensive sentinel research into personnel protection in space. He was a cosmonaut in training for a short period of time, and later had key research and administrative roles in the Soviet space program, providing the final medical certification for cosmonauts prior to liftoff. At the University of Minnesota, he established and was Director, Laboratory for Health and Human Performance in Extreme Environments. This NASA-funded research focused on the development of more effective protective garments for astronauts, firefighters, and other personnel dealing with hazardous materials.

Professor Victor Koscheyev was a highly energetic, creative, personable friend with a great sense of humor who was dedicated to improving the effectiveness of disaster medicine activities. While his last years were extremely challenging, he will be remembered for his courage and his considerable scientific and humanitarian contributions to the world of prehospital and disaster medicine. 